\title{
Discussion on Participatory Publishing and the Digital Transformation of Traditional Publishing*
}

\author{
Yanli Bai \\ College of Literature and Journalism \\ Sichuan University \\ Chengdu, China 610065 \\ School of Journalism and Communication \\ Northwest Minzu University \\ Lanzhou, China 730030
}

\begin{abstract}
In a narrow sense, participatory publishing refers to the active participation of individuals in the publishing process, which is made independent by the claim to freedom of the press as a right and the popularization of technology in the new media environment. However, in terms of the other meaning of participatory production, that is, the trace record in the process of individual participation, although this kind of production is not actively done by any individual, the data to be analyzed is constituted objectively. Since not all data will be shared, the digital transformation of traditional publishing houses is inevitable in the transformation of content and cross-border cooperation.
\end{abstract}

Keywords-participatory publishing; digital transformation of publishing; content transformation; cross-border cooperation

\section{INTRODUCTION}

The popularization of technique application makes it possible for the freedom of the press as a right to operate and to get rid of the requirements of professionalism and specialization. Technology becomes a way of breaking through the restrictions on publishing. As a result, the traditional publishing industry faces the pressure of transformation, and the existing national policies are to be revised based on new technologies, leading to a series of adjustment and release of opinions by the government. It is not that by use of previous technologies the universal liberalization of publishing cannot be achieved, but that the combination of technology costs and publishing policies restricts the social circulation of publications. The issue of publishing is not all about technology. The popularization of technology changes the traditional circulation channels. The change of publishing industry chain in the network and digital environment is the change of the whole public opinion field, not just the change of the publishing industry; after all, it is not the update of pure printing technology.

\section{DEFINITION OF PARTICIPATORY PUBLISHING}

The concept that everyone can make publications holds

*Fund Project: This paper is a project funded by the Central Special fund for basic scientific research operation of colleges and universities of Northwest Minzu University in 2019 (Project No.: 31920190146 ) its validity confirmed in the article 35 of the constitution and relies on the convenience and popularization of technology. As a legal right, the freedom of the press, supported by the technical environment, is more feasible to transform into the publishing autonomy. From the recognition of the freedom of the press by law to the realization of the freedom of the press by technology, the legal provisions and technical reality show two ways to realize participatory publishing. In addition, both approaches are seen from the audience's use of technology (the legality and feasibility of use), which only refers to participatory publishing in a narrow sense.

Participatory publishing has two implications, referring to the active participation of individuals, including the freedom of the press in terms of right appeal and the publishing autonomy under the support of technology in a narrow sense. In terms of whether publishing technology can be freely used by all, the difference between the two lies in that when the publishing technology can only be used by some people, the freedom of the press at the level of political rights becomes one of the appeal ways of participatory publishing, like Milton's claim to the right to a free press in 1644 as well as the movement to balance the international communication order in the second half of last century; however, in the new media environment, when the technological reality makes it possible for everyone to publish, such as many forms of self-publishing, in the methods to achieve participatory publishing, the path of rights appeal takes a back seat. The second meaning of participatory publishing is that in the new media environment, individuals' participation enables more traces to be recorded and retained, which becomes the data to be captured and analyzed by publishers to optimize their publishing resources. In this respect, publishing houses, on the other hand, face difficulties in obtaining data. "Participation" does not merely emphasize that individuals can use communication channels independently. In the history of media, the emergence of new technologies mostly aroused the Utopian imagination of its free use by the whole people. (In the 19th century, for example, Kropotkin and Geddes argued that the power grid and its decentralized nature marked the emergence of a harmonious and 
transparent society. ${ }^{1}$ ), However, history has repeatedly proved that the possibility of technology application does not necessarily become the reality of technology application, and it is not logical to emphasize the universal use of technology. Thus, the second meaning of participatory publishing makes this concept avoid utopian reasoning. For publishers, the traces of individual "participation" make the audience analysis of some published content available.

In terms of the narrow sense of participatory publishing, the right of freedom of publication is confirmed before the technical reality of independent publication is achieved from the respect of time. However, there is no inevitable sequence or substitution relationship between these two implementation paths. Whether in terms of media bias or the history of media change, technology to some extent limits the scope of social behavior. As mentioned above, when a certain communication channel can only be used by some people, the right appeal may be turned to realization by the society. Around 1970, the media reform movement in Western Europe put forward the slogan of the right to communication in view of the monopoly status of radio and television organizations at that time, regarded the right to communication as a human right, and then demanded the non-professionalism of mass communication. ${ }^{2}$ The nonprofessionalism requirement was intended to bridge the gap between communicators and receivers caused by industry monopoly, which was once a right to be fought for. The right to communication, which needed to be called for through political movements, becomes a technological reality to some extent in the new media environment today. "New media constructs a new media environment through its brand new Internet group communication mode, deconstructs the dominant position of mass communication, and manifests the communication in daily life." ${ }^{3}$ The transformation of media technology optimizes the communication environment, and the popularization and plebification of technology make the reading methods of audiences become diversified, which makes it possible for everyone to publish. "Democraticparticipatory media theory" was proposed as a normative theory of rights imagination, but now it has become a descriptive theory in the new media environment. "This theory supports diversified, small-scale, local, nonprofessional and non-institutional mass communication, and supports the role of communicators and receivers changing each other, broadening their horizons and interacting with each other. There are elements of liberalism, socialism, egalitarianism and regionalism as well as elements of idealism in this theory." 4

(French) Armand Mattelart, Michele Mattelaart. Sun Wusan Trans. The History of Communication Theories [M]. Beijing: China Renmin University Press, 2008: 11.

(Poland) Karol Jakubowicz. Zhi Xing Trans. The Masses? Communication? (II) With the Development of Modern Radio and Television, Both Words Have New Meanings [J]. Journal of International Communication. 1986 (2): 16-17.

Hu Yiqing. Reshaping Communication Research Paradigm: Possibility and Feasibility [J]. Modern Communication, 2016 (1): 51

(Poland) Karol Jakubowicz. Zhi Xing Trans. The Masses? Communication? (II) With the Development of Modern Radio and
The second meaning of participatory publishing refers to the data traces of participatory publishing. "Participation" does not mean that any individual uses publishing technology, nor does it mean that there must be communicator/receiver interaction. In terms of behavior, in the new media environment, participation means that the traces of users on the network are recorded in the form of data. For traditional publishing houses, more data can be collected for reference in content selection. As mentioned earlier, these data, while not necessarily accessible, can optimize the publisher's publishing resources. In the perspective of mass communication, the public is understood as the passive receivers of information. In the context of new media, however, the public not only refers to the broad audience group, but also shows its influence on the content production method. With the help of the network platform, the public takes the initiative to participate in the communication, and the professional communicators can analyze a large number of recorded and stored public data, so as to adjust the existing communication activities.

When Jenkins put forward "participatory culture" in 1992 he believed that "new forms of consumption generated by means of new technological means can realize consumers' participation in the production and circulation of media content and successfully create producers' concerns and expectations." 5 However, the creation of concerns and expectation does not mean that it is the initiative of individuals or consumers, but objectively their behavioral data has the possibility of creation of attention and expectation. From the perspective of participatory publishing in a narrow sense, participation makes the audience have the attribute of communicator and endows the production and consumption with new connotation by virtue of network platform. However, from the second meaning of participatory publishing, the difference between the two still exists. The above individual does not create concerns and expectations independently, which indicates that the audience has not disappeared and the dissemination and reception are not necessarily replaced. It is that there are more channels of exchanging between them, more influencing factors between supply and demand, and more possibilities for audiences to express themselves, which undoubtedly reduces the cost of product development in circulation.

\section{DigITAL TRANSFORMATION OF PUBLISHING}

Participatory production gives individuals access to more digital publishing platforms. And the digital transformation of traditional publishers can realize the collection of content data through the cooperation with these digital publishing platforms. Digital publishing transformation does not mean publishers building a digital publishing platform by themselves, but more importantly refers to the transformation of content, that is, obtaining content resources from existing

Television, Both Words Have New Meanings [J]. Journal of International Communication. 1986 (2): 18.

Zhang Hongwei. Participatory Production: Turns and Changes in Cultural Product's Production [J]. Journalism \& Communication, 2015 (11) 110 . 
platforms. In addition, according to the data trace records generated by participatory publishing mentioned above, obtaining and analyzing data records through cooperation with relevant technology providers is conducive to optimizing publishing behavior.

Moreover, publishing is part of the public discourse in a broader sense. "Publishing has long been considered an intellectual and political profession, both in Europe and in Asia". 6 "Due to the changing roles caused by technology, diversity of views and populism often pose a greater threat to mainstream ideological identity creation." 7 Different from the foreign publishing industry driven by the market, China's digital transformation mainly relies on administrative power. Against such background, the change of communication environment and the disharmony of public opinion lead to the transformation of traditional publishing industry driven by administration. In addition, "due to the large differences of consumers in education level, wealth, experience, personality, environment and ability, the participation degree, level, satisfaction and sense of achievement in the production of cultural products are also different, resulting in the 'participatory gap' of consumers." ${ }^{8}$ This participatory gap means the necessity of publishing professionalization, which indicates that it is impossible to de-professionalize publishing. This means that although new technology can improve the possibility of participation in publishing, it may not achieve universal participation. Traditional media is not necessarily doomed to die out, but in order to obtain more traces recorded under participatory behaviors, digital transformation of publishing becomes inevitable, realizing optimization of publishing resources after data acquisition and analysis.

\section{A. Participatory Publishing and Content Transformation}

"Publishing is a branch of the content industry, and no matter how publishing technology changes, its core value will always depend on the value of content-based knowledge and information." ${ }^{9}$ However, the failure of realizing that technology affects the method of content acquisition, and just regarding the two as the relationship between formal carrier and content and considering content to be able to adapt to the endless technological changes make it pointless and unable to unable to accommodate to the current situation of new media technology to emphasize content. In the new media environment, individual participatory publishing means that more data is recorded in the database of technology platform different from the traditional publishing house.

(US) Andre Schiffrin. Bai Xifeng Trans. The Business of Books [M]. Beijing: China Machine Press, 2005: 1

Hu Yiqing. Reshaping Communication Research Paradigm: Possibility and Feasibility [J]. Modern Communication, 2016 (1): 54

8 Zhang Hongwei. Participatory Production: Turns and Changes in Cultural Product's Production [J]. Journalism \& Communication, 2015 (11): 114.

$9 \quad$ Liu Yindi. Opportunities and Challenges Faced by the Book Publishing Industry in the Era of Big Data [J]. Science-Technology \& Publication, 2015 (1): 21-22.
The role of publishing houses in the book industry chain will not be absolute impact, and the traditional paper publishing still has its existence value, but the content and scale will be inevitably adjusted. For publishers and consumers, digitization does not mean the elimination of paper carriers. Since technology makes it possible to integrate different industries, digitization means more consumer involvement in the production process. As for ways of participation, consumers can take the initiative, such as self-financing, or publishers can take the lead, such as obtaining more accurate consumer groups and content trends through data mining, therefore popular or entertainment books will gain better market space. But that doesn't mean technology providers or consumers are dominating the topic. The democracy of technology lies in the fact that technology is not designed to be subservient to a certain user, and the user may not be able to dominate the applications caused by technology.

Digital publishing transformation is the change of publishing content integration method rather than the change of carrier. It is not inevitable to eliminate paper publishing. Therefore, digital publishing transformation does not mean the death of traditional publishing. Some scholars believe that with the development of science and technology, digital processing technology for books and periodicals is becoming easier and easier to implement, the technical threshold will be lower and lower, the advantages of technology providers will be more and more weakened, and the importance of content providers with high-quality content resources in the whole industrial chain will become increasingly prominent. ${ }^{10}$ Such a view assumes that traditional publishers have content resources. This assumption only conforms to existing empirical facts and may not be in line with the future of digital publishing, because technology providers may not necessarily be inferior to traditional publishers when adopting digital technology for content collection and integration. "Electronic publishing, digital publishing is a high-tech field, in which few can consciously step in the publishing community, and even fewer achieve any results. Yet the electronic publishing developers are generally aggressive". ${ }^{11}$

\section{B. Participatory Publishing and Cross-border Cooperation Transformation}

Participatory publishing means that, more data of authors and readers in the traditional sense can be recorded; "there is a huge increase in the data that human beings can 'analyze and use'; and through the exchange, integration and analysis of these data, human beings can discover new knowledge and create new values." ${ }^{12}$ But the databases of technology platforms are not necessarily all shared, and the most

10 Chen Chaoying. Three Paths for Traditional Publishing Houses to Be Transformed to Digital Publishing [J]. Publishing Research, 2010 (7): 58-60.

11 Wang Jianhui, Tang Jin. The Five "Decisive Factors" of the Development of Chinese Publishing Enterprises [J]. Journal of International Communication, 2006 (11): 13

12 Tu Zipei. The Big Data Revolution [M]. Guangxi Normal University Press Group, 2012: 57. 
pressing problem for traditional publishers is not data analysis but data acquisition itself. Only a few publishing companies may be able to develop digital publishing on their own, even with the support of national policies and funds. The question is, even if they can make it, will they be able to collect data of similar value to those offered by technology providers? With interests of multiple parties involved, it is difficult for digital publishing industry to be exclusive to a certain enterprise.

Given that data traces of participatory production are more often recorded by technology platform providers, and many of these resources are not public or shared, in order to optimize publishing resources in a digital environment, it is important to have access to the content. Faced with the digital transformation, many publishing houses' self-built websites "are not real digital publishing business models, and the results may not bring more benefits than some influence that certain single brands may gain." 13

Now that digitization and the Internet have become the industry's context, rather than a single internal technological change, it is not just publishing that needs to change as an industry, and therefore the digital transition of publishing is not something that publishers can undertake independently. "At present, China's fragmentation is very serious, with excessive classification of publishing categories, distinct barriers between the publishing industry and television, radio, newspapers, audio and video media. Therefore to become bigger and stronger, China's publishing industry must break down the barriers between the media." ${ }^{14}$ In view of this, update through cooperation and integration with related technology industries rather than self-preservation, is the lowest-cost way to face the digital environment. "Digitization brings together the previously distinct information, communication and mass media industries" ${ }^{15}$. "With the advent of the Internet, the line between publishing and film, television, entertainment, IT and other industries has become increasingly blurred. Other industries can be involved in publishing in various forms and publishing can also be involved in media, entertainment, and education and so on." 16 Technology provides more possibilities and opportunities for individual consumers to participate in communication and de-professionalization is not only a certain link in the publishing industry chain, but also the integration of different industries and publishing industry. "Participatory production strives to provide an open environment and opportunities for mass consumers to

13 Zhang Wenyang. Misunderstanding in the Transformation of Small and Medium-sized Publishing Houses Against the Digital Background [J]. Editorial Friend, 2013 (5): 27.

14 Xiao Dongfa, Zhang Wenyan. From Traditional Publishing to Trans-Media Era: Discussing the Development of Editorial and Publishing Education in China [J]. Journal of International Communication, 2006 (11) 17.

15 Min Dahong. Digital Wave of Electronic Media [J]. Journal of International Communication, 1997 (4): 26.

16 Zhang Ru. Publishing Digitization and Network Publishing [J]. Publishing Journal, 2002 (1): 54. participate, and advocates close cooperation between producers and consumers." 17

In different periods of technology application, the country issue corresponding publication policies. If publishing houses make adaptive changes by themselves, it is not just about the change of talent and management structure, but also the capital guarantee of technical input, which is not affordable for all publishing houses. In addition, the flooding of changes will cause the intermingling of good and bad. The accordingly emerging publishing platforms or digital standards are not conducive to attracting attentions. For example, "the content resources of one publishing group cannot attract readers from large digital publishing platforms such as Amazon. Many foreign publishing groups have set up their own e-book sales platforms, but they have cancelled this business because of the low traffic and sales volume." 18

From this point of view, the "Guidance on Promoting the Integrated Development of Traditional Publishing and Emerging Publishing" issued by the state conforms to the industry reality of the publishing industry and the technical reality of the digital environment. This industry integration reflects the trend of breaking the isolation between different industries to obtain economic output. "In the context of the ever-changing information technology revolution, technology is never a strong suit for publishing companies... The best choice for traditional publishing companies is to form a benign integration with new media companies... so as to really break down the media segmentation, the market segmentation and the geographical segmentation." ${ }^{19}$ Even if more new technologies emerge in the future, they should be more conducive to participatory production just as digitization has been covered by such concepts as digitization or big data. The fact that production and consumption still exist, does not mean the melting of the boundaries between production and consumption. "The distance between sender and receiver is not always a gap to fill", ${ }^{20}$ but there will be more ways for the two to communicate in the production process, which will certainly be supported by new technologies. The deprofessionalization and participatory publishing do not just refer to the active participation in communication or the interaction with the media of individual consumers. In terms of data analysis, the de-professionalization under new media technology means that more data are recorded and need to be analyzed, so that traditional publishing houses can achieve accurate topic selection or marketing, and the importance of

17 Zhang Hongwei. Participatory Production: Turns and Changes in Cultural Product's Production [J]. Journalism \& Communication, 2015 (11): 113.

18 Liu Yinti, Su Hongyuan. Comparative Study on Digital Transformation Paths of Publishing Groups at Home and Abroad [J]. China Publishing Journal, 2015 (19): 66.

19 Zhong Jianhua, Wang Yafei, Liu Chengyong. Common Reflections on the Transition from Traditional Publishing to Digital Publishing [J]. Chinese Editorials, 2010 (6): 55.

20 (US) John Durham Peters. He Daokuan Trans. Speaking into the Air - A History of the Idea of Communication [M]. Beijing: Huaxia Publishing House, 2003: 50. 
content is reflected in the technical method of positioning content.

Although the digital platform of the network is the main carrier of audience participation and has data advantages, and "open platform gives the public the right to participate completely, but due to the characteristics of the public platform" ${ }^{21}$, the production of authoritative content is in danger. This provides the possibility of cooperation between technology providers and traditional publishing houses, and shows that industry transformation is not only about technology. With the existing policies and industry rules unchanged, traditional publishing houses or technology providers cannot complete the transformation independently, so the interests of the digital publishing industry cannot be enjoyed by only one.

As the network orientation, animation orientation and gamification of publishing and its cross-border cooperation have become important trends of traditional publishing, "Playing games online and reading novels offline have become an important part of communication between players. The abundance of offline content and the complimentary gifts will make these readers willing to pay for paper books." 22 This shows that publishing transformation is not only about the change of publishing media in terms of its network orientation or digitization. The reason why digital publishing is a change of the whole publishing industry is different from the historical evolution of publishing technology of books from engraving to machine printing. For a long time, publishing was more about buying new technology and equipment. Today, in a digital environment, publishers' challenge comes more from content, which cannot be covered by the empty, non-operational phrase "content is king". Digital publishing can be a completely marketized behavior at first, but in reality, it is mainly driven by policies, which shows that as the pass of public opinion field and an important circulation channel, publishing has the responsibility of ideological monitoring under digital environment in addition to better content service. Therefore, publishing in the digital environment is not just a change of media.

\section{CONCLUSION}

Participatory publishing has two implications, and it first refers to the active participation of individuals, including the freedom of the press in terms of right appeal and the publishing autonomy under the support of technology. Secondly, it means that in the new media environment, more traces can be recorded and retained due to individuals' participation, so that publishers can capture and analyze data to optimize publishing resources. Yet as for the second meaning, publishing houses are faced with difficulties in

21 Research Group of "Tracking Research on Frontier Issues of Journalism and Communication at Home and Abroad". Citizen Journalism, Alternative Journalism and Others in the Digital Age: Debate and Evaluation [J]. Journalism \& Communication, 2015 (12): 110.

22 Wei Jie, Li Jian. Exploration on the Development of Online Game Publications of Traditional Publishing Houses: Taking the Publication of DNF Series Books as an Example [J]. Publishing Research, 2015 (12): 28. obtaining data. "Participation" not only emphasizes that individuals can independently use communication channels, so the second meaning of participatory publishing avoids Utopian reasoning. For publishers, the traces of individual "participation" make the audience analysis of some published content available.

Participatory production enables individuals to access more self-publishing platforms. While the digital publishing transformation of traditional publishing houses can achieve the collection of content data through the cooperation with existing self-publishing platforms, the digital publishing transformation does not mean building a digital publishing platform by oneself, but more refers to the transformation of content, that is, obtaining content resources from existing platforms. By cooperating with relevant technology providers, obtaining and analyzing data can help optimize publishing behavior, which is also a low-cost way for publishing houses to realize their transformation.

\section{REFERENCES}

[1] (French) Armand Mattelart, Michele Mattelaart. Sun Wusan Trans The History of Communication Theories [M]. Beijing: China Renmin University Press, 2008: 11.

[2] (Poland) Karol Jakubowicz. Zhi Xing Trans. The Masses? Communication? (II) With the Development of Modern Radio and Television, Both Words Have New Meanings [J]. Journal of International Communication. 1986 (2): 16-17.

[3] $\mathrm{Hu}$ Yiqing. Reshaping Communication Research Paradigm: Possibility and Feasibility [J]. Modern Communication, 2016 (1): 51. (in Chinese)

[4] (Poland) Karol Jakubowicz. Zhi Xing Trans. The Masses? Communication? (II) With the Development of Modern Radio and Television, Both Words Have New Meanings [J]. Journal of International Communication. 1986 (2): 18.

[5] Zhang Hongwei. Participatory Production: Turns and Changes in Cultural Product's Production [J]. Journalism \& Communication, 2015 (11): 110. (in Chinese)

[6] (US) Andre Schiffrin. Bai Xifeng Trans. The Business of Books [M] Beijing: China Machine Press, 2005: 1.

[7] $\mathrm{Hu}$ Yiqing. Reshaping Communication Research Paradigm: Possibility and Feasibility [J]. Modern Communication, 2016 (1): 54. (in Chinese)

[8] Zhang Hongwei. Participatory Production: Turns and Changes in Cultural Product's Production [J]. Journalism \& Communication, 2015 (11): 114. (in Chinese)

[9] Liu Yindi. Opportunities and Challenges Faced by the Book Publishing Industry in the Era of Big Data [J]. Science-Technology \& Publication, 2015 (1): 21-22. (in Chinese)

[10] Chen Chaoying. Three Paths for Traditional Publishing Houses to Be Transformed to Digital Publishing [J]. Publishing Research, 2010 (7): 58-60. (in Chinese)

[11] Wang Jianhui, Tang Jin. The Five "Decisive Factors" of the Development of Chinese Publishing Enterprises [J]. Journal of International Communication, 2006 (11): 13. (in Chinese)

[12] Tu Zipei. The Big Data Revolution [M]. Guangxi Normal University Press Group, 2012: 57. (in Chinese)

[13] Zhang Wenyang. Misunderstanding in the Transformation of Small and Medium-sized Publishing Houses Against the Digital Background [J]. Editorial Friend, 2013 (5): 27. (in Chinese)

[14] Xiao Dongfa, Zhang Wenyan. From Traditional Publishing to TransMedia Era: Discussing the Development of Editorial and Publishing Education in China [J]. Journal of International Communication, 2006 (11): 17. (in Chinese) 
[15] Min Dahong. Digital Wave of Electronic Media [J]. Journal of International Communication, 1997 (4): 26. (in Chinese)

[16] Zhang Ru. Publishing Digitization and Network Publishing [J]. Publishing Journal, 2002 (1): 54. (in Chinese)

[17] Zhang Hongwei. Participatory Production: Turns and Changes in Cultural Product's Production [J]. Journalism \& Communication, 2015 (11): 113. (in Chinese)

[18] Liu Yinti, Su Hongyuan. Comparative Study on Digital Transformation Paths of Publishing Groups at Home and Abroad [J]. China Publishing Journal, 2015 (19): 66. (in Chinese)

[19] Zhong Jianhua, Wang Yafei, Liu Chengyong. Common Reflections on the Transition from Traditional Publishing to Digital Publishing [J]. Chinese Editorials, 2010 (6): 55. (in Chinese)

[20] (US) John Durham Peters. He Daokuan Trans. Speaking into the Air - A History of the Idea of Communication [M]. Beijing: Huaxia Publishing House, 2003: 50

[21] Research Group of "Tracking Research on Frontier Issues of Journalism and Communication at Home and Abroad". Citizen Journalism, Alternative Journalism and Others in the Digital Age: Debate and Evaluation [J]. Journalism \& Communication, 2015 (12): 110. (in Chinese)

[22] Wei Jie, Li Jian. Exploration on the Development of Online Game Publications of Traditional Publishing Houses: Taking the Publication of DNF Series Books as an Example [J]. Publishing Research, 2015 (12): 28. (in Chinese) 